\title{
PESQUISA-PESQUISADOR/A VISCERAL - URGÊNCIA, EMERGÊNCIA E GENEALOGIA DAS CATEGORIAS
}

\author{
VISCERAL RESEARCH AND VISCERAL RESEARCHER - \\ URGENCY, EMERGENCY AND GENEALOGY OF CATEGORIES
}

Rodrigo Torquato da Silva ${ }^{46}$

\section{Resumo}

O presente artigo é resultado de dez anos de pesquisas. Pretende-se, aqui, condensar um conjunto de problematizações, que permitiram construir duas categorias teóricometodológicas de análises: Pesquisa e Pesquisador/a Visceral. O objetivo é estabelecer uma compreensão possível, acerca da complexidade de pesquisar COM as Favelas e "Quebradas", levando em consideração a minha experiência de professor, em escolas públicas, e de ex-morador-praticante-observador, por 38 anos, da favela da Rocinha-RJ.

Palavras-chave: Pesquisa-pesquisador(a) visceral. Escola. Favela.

\section{Abstract}

This article is the result of ten years of research. It is intended, here, to group a set of problematizations, which allowed the construction of two theoretical and methodological categories of analysis: Visceral Research and Visceral Researcher. The objective is to establish a possible understanding, about the complexity of researching WITH Favelas and "Quebradas", taking into account my experience as a teacher, in public schools, and as an ex-resident-practitioner-observer, for 38 years, in the Rocinha slum.

Keywords: Research and Visceral Researcher. School. Shanty town.

\footnotetext{
${ }^{46}$ Rodrigo Torquato da Silva é Professor Associado e líder do Grupo de Pesquisa ALFAVELA, no IEAR - UFF. Advogado, integrante da Comissão de Direitos Humanos da OAB - Maricá / RJ. Instituto de Educação de Angra dos Reis - Universidade Federal Fluminense. E-mail: rtorquato@id.uff.br. Telefone: (21) 98651-7058. ORCID: https://orcid.org/0000-0001-8381-3821.
} 


\section{RevistAleph}

\section{Introdução}

A concepção aqui defendida firma-se na ideia de que uma categoria-conceito não se origina exclusivamente do intelecto de um sujeito, sem estabelecer conexão com sua imersão no mundo. Dito de outra forma, uma categoria-conceito, tal como nos ensinou Marx, emerge das interações sociais, ou seja, é uma relação social. Assim, é possível apresentar a gênese e as relações sociais que possibilitaram a emergência das categorias "Pesquisa-Pesquisador Visceral".

\section{As primeiras rotas}

Ao iniciar a minha pesquisa para o doutorado em Educação, na UFF, tinha o intuito de compreender e discutir as questões políticas, sociais e culturais que sempre fizeram parte das minhas circunstâncias existenciais, já que sou "Cria" da Favela da Rocinha, no Rio de Janeiro. Os referenciais teórico-metodológicos com os quais mantinha diálogo iam desde Marx até as pesquisas com os cotidianos das escolas que atendiam os/as estudantes das Classes Populares (Regina Leite Garcia/ GRUPALFA-UFF e Nilda Alves/PROPEd - UERJ).

Tais estudos levaram-me à busca pela compreensão do que se passava nos espaços escolares que atendiam predominantemente as Classes Populares, já que tinha me tornado, por via de concurso público, professor das séries iniciais do Ensino Fundamental. As pesquisas bibliográficas mostraram-me uma produção profícua no Campo das Pesquisas com os cotidianos escolares.

A pesquisadora Nilda Alves (1998, p. 130 - 131), por exemplo, ao apresentar a sua Tese de Livre Docência, sob forte influência de Michel de Certeau, ainda na década de 90, fez a seguinte proposição:

A escola é, assim, também espaço, pois em movimento, expressão das "táticas", lugar praticado, pleno de "operações", devidas a ações de sujeitos históricos (o professor que consegue ensinar a ler e a escrever; o aluno que aprende e se recusa a aprender bobagens; o diretor que consegue pintar a escola todos os anos; a cozinheira que com os mesmos ingredientes de todas, faz uma merenda deliciosa). Esse espaço tenta se criar/fazer no próprio já apropriado, no lugar da ação estratégica do poder político que com uma regularidade, que poderíamos dizer assustadora, se atualiza para permanecer igual. Por isso mesmo, a escola-espaço vai se caracterizar: pelo tempo presente - pois o uso se faz agora; pela descontinuidade - já que são usadas só algumas coisas do lugar e só se 


\section{RevistAleph}

criam algumas possibilidades aqui e ali de espaços; pelo fático - pois são eleitos os espaços que se fazem: como a minha sala (...). Na memória, de tantas inaugurações assistidas, só algumas aparecem, mas, sobretudo, de usos feitos selecionam-se alguns, que se tende a aproximar do que se sabe do presente (...).

A busca por métodos que pudessem consolidar o Campo de Pesquisa com o Cotidiano levou-me aos estudos da pesquisadora Regina Leite Garcia, Líder do GrupalfaUFF, na tentativa de superar a miopia desenvolvida pelos métodos adaptados das ciências exatas para as pesquisas educacionais (especialmente as pesquisas que sobrevalorizavam as Estatísticas por amostragem). Os resultados das pesquisas do Grupalfa - UFF contribuíram muito para ampliar o foco das lentes metodológicas e ir além das sombras criadas pelos ditos métodos das ciências duras aplicadas ao Cotidiano escolar.

Entre as inúmeras publicações do Grupo, merecem destaque aquelas que se propuseram a enfrentar o complexo debate acerca dos métodos e contramétodos (GARCIA, 2003) adotados nas pesquisas com as escolas públicas, especialmente aquelas inseridas nos contextos das Classes Populares.

Assim, justifica-se a citação abaixo, extraída do artigo “A difícil arte/ciência de pesquisar com o cotidiano", pois é lapidar para a compreensão do que está sendo dito. Nela, aponta Regina Leite Garcia (2003, p. 205-206):

Em nossas pesquisas com o cotidiano escolar temos observado como as professoras vão se tornando pesquisadoras de suas próprias práticas. 0 que temos constatado é que à medida que a professora vai se tornando mais e mais comprometida com a aprendizagem d@s alun@s e inconformada com o fracasso escolar, se põe a refletir sobre o que acontece no cotidiano da sala de aula, de modo que, a partir do melhor compreendido, possa criar alternativas pedagógicas mais capazes de contribuir para o sucesso de tod@s @s alun@s e não apenas de alguns e algumas. Começa a se fazer perguntas sobre o processo de ensinar e aprender, tentando melhor compreender a reação de cada alun@ ao que pretende ensinar. Às perguntas que se faz, procura em suas reservas teóricas explicações e, quando não as encontra, busca o coletivo da escola para compartilhar o seu ainda não saber e a sua procura de novos saberes que possam ajudar a encontrar respostas teóricas. O diálogo daquele coletivo, na verdade, um rico polílogo, sobre as diferentes práticas pedagógicas, é um momento rico de trocas e de hibridização, conforme Bhabha, em que cada professora trazendo os seus fracassos e sucessos, as suas dúvidas e buscas, os seus saberes e não saberes, vai participando de um processo coletivo de transformação. Aprendem com as colegas, ensina com as colegas e, ao final de cada reunião pedagógica, ninguém é mais @ mesm@,pois tod@s mudaram, hibridizad@s que foram no processo de aprendercom@outr@eensinara/ao outr@. 
Cabe ressaltar, também, no mapeamento das rotas teórico-metodológicas traçadas aqui, a importância dos estudos do professor-pesquisador Victor Valla, da UFF, acerca das Políticas para as Favelas do Rio de Janeiro, no período entre os anos de 1940-1985, com destaque para a Obra "Educação e Favela", datada de 1986.

Ao analisar as Políticas intervencionistas, do período supracitado, a partir do Relatório SAGMACS, Valla (1986, p. 195) aponta que

A nível de constatação, reunindo todos os aspectos analisados, - polícia, religião etc. - é possível concluir que há características comuns a todas as intervenções. De uma maneira genérica, pode-se dizer que a relação desses grupos com os moradores de favelas é uma relação de dominação, repressão (física e moral), controle, vigilância e fiscalização. Transparece a convicção de que os populares (moradores de favelas, nesse caso) são ignorantes, sem "valores", "malandros", desrespeitosos, malcomportados, preguiçosos, sem iniciativa. Enfim, "não têm jeito".

Ou seja, os métodos adotados nessas pesquisas não só orientavam o olhar dos pesquisadores que os aplicavam, mas, sobretudo, construíam-criavam um perfil do morador de favela observado (objetificado). Tais métodos, em vez de ajudarem a compreender as condições materiais que levavam os moradores de favelas a aquele enquadramento metodológico, na verdade, os objetificavam, estigmatizando-os discursivamente para atender aos interesses políticos-econômicos das classes (e dos grupos) que financiam as pesquisas e seus respectivos pesquisadores.

Por fim, porém não menos importante, não se pode deixar de fora dessa cartografia as importantes contribuições para o Campo do Cotidiano, em especial na Área de Currículos, da professora-pesquisadora Inês Barbosa (PROPEd/UERJ). Suas pesquisas vêm apontando para a valorização dos conhecimentos forjados fora da escola, que, ao passarem a fazer parte do cotidiano escolar, passam a tecer os Currículos Praticados no cotidiano escolar.

Como exemplo, vejamos o que diz a autora (OLIVEIRA \& SGARBI, 2001, p.33) acerca do uso das imagens enquanto possibilidades metodológicas, ao analisar algumas fotografias de crianças dentro e fora da escola, do fotógrafo Robert Doisneau:

A primeira e mais importante questão que gostaria de abordar nesse texto refere-se ao quanto aprendemos na vida cotidiana, através de mecanismos que não sabemos descrever ou explicar, mas que formam o que sabemos e o que pensamos sobre os mais diversos temas, 


\section{RevistAleph}

contribuindo, portanto, para as nossas ações e sobre as relações com o mundo à nossa volta. Inúmeros são os exemplos de situações que evidenciam a presença desses tipos de aprendizagem em nossas vidas e da indissociabilidade entre os saberes tecidos na vida cotidiana - através dessas aprendizagens do que não nos é explicitamente ensinado - e os chamados saberes formais, ensinados nas escolas.

O que nos sugere a pesquisadora é a hipótese de que existem mecanismos que formam o que pensamos e o que sabemos, de uma maneira que não sabemos explicar. Nesse sentido, a urgência na construção de métodos que extrapolem os limites da linearidade cartesiana se justifica. Ou seja, na medida em que se valorizam algumas especificidades, tais como as fotografias de família ou de escola, amplificam-se as possibilidades de melhor compreender aquilo que não é captado com os métodos "universalistas-generalizantes".

Desta forma, faz-se urgente a busca por metodologias que permitam melhor compreender o que se passa nos cotidianos das favelas. Sem isso, torna-se embaçada a compreensão de como os currículos acontecem nesses espaços educativos cotidianos.

\section{O grande dilema teórico-metodológico}

A partir desses referenciais, aos poucos, fui traçando rotas metodológicas, tentando achar caminhos que melhor ajudassem a transformar as minhas vivências, na favela e nas escolas públicas onde lecionava (nos municípios de Niterói e Duque de Caxias), em reflexão crítico-política que consubstanciasse as bases científicas da minha Tese de Doutoramento.

A primeira constatação foi a de que as teorias nas quais me baseava não eram suficientes para abarcar as situações que eram vivenciadas nas Favelas ou em Quebradas (categoria muito utilizada em São Paulo). Por conta disso, tais situações foram transformadas em problemáticas, que possibilitavam compreender melhor as questões daqueles cotidianos. Ou seja, os conhecimentos oriundos das vivências nas favelas e nas escolas públicas representavam a força motriz que norteava a minha base teórica, configurando-se como teorias em movimento.

Algumas situações levaram-me a indagações, de caráter fundamental, que permitiram traçar as rotas de estudos e de análises para a Tese: existem enredamentos das sociabilidades violentas da favela no cotidiano das escolas pesquisadas? Tais sociabilidades 


\section{RevistAleph}

têm impactado o cotidiano e/ou os currículos das escolas? Que tipos de impactos? Seriam impactos (como algo que vem de fora) ou enredamentos, entrelaçamentos, amálgamas?

O grande enigma era estabelecer uma compreensão analítica possível entre as estruturas-estruturantes das ações e das interações sociais. A questão fundamental era tentar compreender as relações sociais que se passavam nas escolas investigadas a partir da minha experiência de 38 anos como morador-praticante-observador das relações cotidianas na favela da Rocinha-RJ, visto que se tratava de contextos situados em lugares distantes e diferentes.

Tal dilema foi resolvido a partir do Exame de Qualificação do meu Doutoramento, com a extraordinária contribuição da Profa Ana Clara Torres Ribeiro (LASTRO-UFRJ), que elucidou o problema empírico-metodológico da pesquisa, conduzindo, de forma muito clara, à categoria-conceito de PESQUISA-PESQUISADOR VISCERAL. De acordo com Silva (2012, p. 173):

(...) Segundo ela, estávamos diante de uma pesquisa que era a afirmação de uma nova forma de refletir/intervir na experiência social, com seus rebatimentos na reflexão da metodologia de pesquisa. Para além da pesquisa-ação, da pesquisa-intervenção, o que tínhamos ali era uma pesquisa visceral. Nesse novo tipo de pesquisa, ressaltava ainda, o pesquisador comprometido com a reflexão/exposição da pesquisa visceral pode permitir a reflexão do ser humano e as suas circunstâncias. Ou seja, um dos nortes da presente escrita de pesquisa permite a reflexão das configurações históricas das identidades sociais e os processos de identificação. Por outro lado, a reflexão de suas circunstâncias permite a introdução das dimensões da opressão, do contexto, do lugar, do espaçotemporalidade da ação.

O que a reflexão acima permite afirmar é que não é possível construir uma Ciência Social sem considerar a Pesquisa e o/a Pesquisador/a Visceral como alguém que desenvolve a sua pesquisa encarnando a escrita na experiência das suas circunstâncias existenciais. Não se trata aqui da exaltação pretensiosa de um ineditismo teórico-metodológico, que desconsidera ou desqualifica os outros tipos e modalidades de pesquisas precedentes. $\mathrm{Na}$ perspectiva aqui defendida, deixamos claro em trabalho anterior, publicado nessa revista, sob autoria de Silva e Alves (2014, p. 38-39), que

[...] não estamos atravessando ninguém, que a gente fala a partir da nossa própria experiência. A pesquisa prescinde do atravessamento do outro. [...] há contextos, sujeitos e temporalidades diferentes que formam os nexos empíricos e nos permitem a valorização da experiência dos pesquisadores que expõem as próprias vísceras. Próximos e expostos, temos os corpos 


\section{RevistAleph}

abertos por situações de natureza semelhante. O que chamamos por visceralidade impossibilita o distanciamento pregado pelo paradigma cientificista. Também, em nossas pesquisas, procuramos uma postura distinta à proximidade contemplativa ou de uma mistura ou de uma diluição total em que as implicações são impossíveis.

Vimos apontando também, no mesmo trabalho citado (Ibidem, p. 39), para a necessidade de mudar a forma como são concebidas as crianças na relação com as pesquisas:

\footnotetext{
Em nossas pesquisas, as crianças não são apenas celebradas e deixadas sozinhas na sua experiência como algo de impossível compreensão e conhecimento, porque entendemos que os pequenos dividem conosco, as questões urgentes que implicam a opressão humana.

No sentido da visceralidade, não podemos expor ou usar o outro (no caso as crianças), não por uma escolha metodológica, mas por uma condição sine qua non dos pesquisadores, que ao interagirem com esses contextos, encontram ressonâncias em suas próprias marcas, ou seja, expõem suas próprias vísceras.
}

Ante o exposto, as contribuições apontadas acima, ainda que incipientes, e sem nenhuma pretensão de definitividade - portanto, em construção - , tornam-se bastante relevantes na medida em que justificam a valorização dos/das Pesquisadores Viscerais e suas vivências na/com as Favelas e Quebradas, fortalecendo a conexão entre os contextos em que estão inseridos - incluindo a escola. Dessa forma, como ponto de partida da pesquisa, estão as entranhas das suas experiências e relações sociais-humanas-culturais, o que envolve lidar com grupos não estatais armados e a sociabilidade violenta decorrente, além de normas impostas que são distantes daquelas positivadas no Ordenamento Jurídico oficial.

\section{Urgência para além da emergência das categorias Pesquisa-Pesquisador/a Visceral}

Ante tudo que foi exposto, até aqui, é possível constatar que estamos diante de algo novo, pois, ao valorizar e transformar as experiências dos/as pesquisadores/as oriundos dos contextos de Favelas e Quebradas, onde o capitalismo se revela mais desumano e cruel, as Pesquisas Viscerais possibilitam críticas inovadoras.

No entanto, os/as Pesquisadores/as Viscerais, ao problematizarem a própria condição existencial, nesses contextos, são muitas vezes criminalizados e estigmatizados. Suas críticas trazem consequências factuais para si, tais como, ver o seu patrimônio na (c) (i) () 


\section{RevistAleph}

favela ser confiscado, sob jugo de grupos armados não estatais, com expulsão compulsória do morro. Ameaçados de perderem a própria vida, juntamente com a sua família, precisam abandonar tudo o que construíram na Favela. Isso é a essência da ideia de expor as próprias vísceras.

Além disso, o conhecimento trazido pelo/a Pesquisador/a Visceral muitas vezes é considerado pelos grandes Centro Acadêmicos como mero senso comum, sem valor científico, pois não foi enquadrado na "terceira pessoa", conforme os ditames das normas academicistas, que constroem conhecimentos "desencarnados", distantes da realidade social brasileira.

Desse modo, os/as Pesquisadores/as Viscerais, ao narrarem os contextos nos quais estão inseridos, são obrigados a expor as próprias vísceras, isto é, as suas NARRATIVAS VISCERAIS, criam uma vulnerabilidade para si, pois, após narrar, são obrigados a conviver com as consequências que a sua narrativa vai gerar.

As vísceras existenciais do/da Pesquisador/a se materializa numa relação social em que a reflexão crítica acerca da sua vivência com a história local cria os nexos necessários para a conexão dos contextos com a produção de conhecimento científico, o que configura a Pesquisa Visceral. Ou seja, o/a Pesquisador/a Visceral é um sujeito do conhecimento comprometido politicamente que, ao se valorizar na pesquisa, enquanto sujeito, cria nexos entre contextos históricos diferentes, que amalgamam a sua biografia às histórias locais.

O/a Pesquisador/a Visceral estuda aquilo que expõe as próprias vísceras, tentando compreender as Favelas e as Quebradas das suas experiências, percebendo que está dentro e fora, ao mesmo tempo, daquilo que pesquisa. Não há como esse/a pesquisador/a se distanciar dos marcos históricos e identitários que o/a constroem.

Estamos diante de uma situação nova e inovadora para as pesquisas sociais, que não pode ser castrada, pois o/a Pesquisador/a Visceral, que está emergindo das Classes Populares às universidades, por meio das lutas sociais, tais como as políticas de Cotas Raciais, é crucial para o desenvolvimento das Ciências Sociais e as consequências positivas que daí emergirão. É absolutamente necessário valorizar esse tipo de Pesquisa, pois é aí que se criam os nexos empíricos lógicos e suficientes para a coerência de uma Ciência Social conectada com a realidade do seu país. O/A pesquisador/a visceral tem nas suas vísceras as várias experiências que o/a ligam aos múltiplos contextos da sua pesquisa. 


\section{RevistAleph}

É importante frisar que tal pesquisa não pretende elaborar uma "metametodologia" que inclua todos os níveis e dimensões de relação e interação social com os contextos das Favelas e Quebradas. Não se trata de sugerir, ingenuamente, que só um de "dentro" da Favela é capaz de alcançar uma realidade mais concreta ou uma "verdade" dos fatos mais pura, acerca das lógicas que se tecem nas Favelas e Quebradas.

O que se quer é problematizar a eficácia da relação que se estabelece entre pesquisador e "objeto", como uma relação de interioridade-exterioridade, em que a cada instante em que somos surpreendidos na pesquisa, nos tornamos outro/a pesquisador/a, diferente do que éramos antes da surpresa, pois não somente o que está sendo pesquisado se torna outra coisa, diferente daquilo que enxergávamos anteriormente, como também o/a própria Pesquisado/a Visceral se transforma ao tomar consciência daquilo que passa no seu contexto, visto por outra lente.

É assim que se torna relevante a história de vida do/a Pesquisador com as Favelas e Quebradas. A Narrativa Visceral permite posicionar os interlocutores e situar o/a pesquisador/a, e não estou falando aqui de lugar de fala, mas de posicionamento políticocrítico e revolucionário, pois os/as interlocutores/as poderão dialogar com os sentidos que se relacionam com a experiência de vida de quem sobrevive em circunstâncias limites, tais como o/a trabalhador/a morador de Favelas e Quebradas.

Diante do que foi exposto, é possível afirmar que o que está em jogo nas Pesquisas Viscerais não é uma discussão simplista sobre uma disputa entre paradigmas acadêmicos, de razão cartesiana (cujas pesquisas fundam-se na hipervalorização de dados matematizáveis, universais), e as singularidades ou idiossincrasias dos/das pesquisadores/as Viscerais. É, sim, a valorização das experiências desses sujeitos no processo de construção de conhecimento científico. Ou seja, trata-se da chegada e não da partida de seus contextos.

\section{Para não concluir...}

Expor as próprias vísceras dialoga com uma concepção presente no Candomblé, na Umbanda e, naturalmente, nas Favelas e Quebradas, que é a ideia de 'corpo fechado'. Abrir o corpo do/a Pesquisador/a Visceral, distante do objeto, nos permite não tomar o singular como uma particularidade estrita, mas sim, nos perceber habitados por singulares que nos 


\section{RevistAleph}

atravessam e ampliam as nossas possibilidades de pesquisar. Assim, as vísceras são aberturas, ou seja, zonas de possibilidades e de indiscernibilidade que nos equalizam nas situações de opressão.

Dito de outra forma, é a condição de opressão que rompe as distâncias ou proximidades fabricadas por discursos metodológicos, desencarnados de um corpo que sofre factualmente as consequências do capitalismo e permite a emergência de novos sentidos nas aberturas dos corpos/corpus fechados. "Aos viscerais é possível ler o que está em jogo, ou seja, riscos e tensões naquilo que vemos como situações cotidianas. São pesquisas viscerais, na carne que se faz verbo e do verbo que se faz navalha" (SILVA, ALVES \& COLLET, 2014, p. 38).

\section{Referências}

ALVES, Nilda. O espaço escolar e suas marcas: o espaço como dimensão material do currículo. Rio de Janeiro: DP\&A, 1998.

GARCIA, Regina Leite. (Org.) Método; Métodos; Contramétodo. São Paulo: Cortez, 2003.

OLIVEIRA, Inês Barbosa \& SGARBI, Paulo (Orgs). Fora da escola também se aprende. Rio de Janeiro: DP\&A, 2001.

SILVA, Rodrigo Torquato da. Escola-Favela e Favela-Escola: "esse menino não tem jeito!". Petrópolis, RJ: De Petrus et Alii: Rio de Janeiro: FAPERJ, 2012.

SILVA, Rodrigo Torquato; ALVES, Luciana Pires; COLLET, Heitor. Alfavela: Pesquisas viscerais em Educação. Lisboa/Portugal: Chiado, 2014.

SILVA, Rodrigo Torquato da; ALVES, Luciana Pires. Eu era a carne, e agora, sou a própria navalha pesquisas viscerais em alfabetização. Revista Aleph - UFF. Online, ANO X - Número 21. pp. 20 - 40, Julho, 2014. Disponível em https://periodicos.uff.br/revistaleph/article/view/38939/22378.

Consultado em 20/10/2019.

VALLA, Victor Vincent. Educação e Favela: políticas para as favelas do Rio de Janeiro, 1940 - 1985. Petrópolis, RJ: Vozes, 1986. 